\title{
Teores de carboidratos em mangueira 'Ubá' submetida a diferentes doses de paclobutrazol
}

\section{Carbohydrates content in 'Ubá' mango tree submitted to different doses of paclobutrazol}

\author{
Girlaine Pereira Oliveira ${ }^{1^{*}}$, Dalmo Lopes de Siqueira², Paulo Roberto Cecon ${ }^{3}$ \\ e Luiz Carlos Chamhum Salomão²
}

\author{
${ }_{1}^{1}$ Departamento de Fitotecnia, Escola Superior de Agricultura “Luiz de Queiroz" - ESALQ/USP, Piracicaba SP, Brasil \\ 2 Departamento de fitotecnia, Universidade Federal de Viçosa - UFV, Viçosa MG, Brasil \\ ${ }^{3}$ Departamento de Estatística, Universidade Federal de Viçosa - UFV, Viçosa MG, Brasil \\ ( ${ }^{*}$-mail: girlaine.pereira@usp.br) \\ http://dx.doi.org/10.19084/RCA18016
}

Recebido/received: 2018.01.19

Recebido em versão revista/received in revised form: 2018.04.06

Aceite/accepted: 2018.04.23

\section{R E S U M O}

O uso do paclobutrazol em mangueiras é bastante difundido nas regiões tropicais, uma vez que desempenham importante função de promover a floração, permitindo o escalonamento da produção. Além da floração, o paclobutrazol pode influenciar outras características, como porte, concentração de carboidratos e alterar a cor verde nas folhas. Nesse contexto, o trabalho avaliou as relações entre características vegetativas e concentrações de carboidratos em plantas de mangueira 'Ubá' submetidas a diferentes doses de paclobutrazol (PBZ). Em abril de 2014 o PBZ foi aplicado em mangueira conduzidas em arranjo fatorial $5 \times 2+1$, sendo 5 doses de paclobutrazol ( $0 ; 0,50 ; 1,00 ; 1,50$ e 2,0 g(i.a) por metro linear de copa), com e sem desponte dos ramos e uma testemunha adicional que não recebeu nenhum dos tratamentos descritos. O delineamento foi em blocos casualisados, 4 repetições e, em cada bloco foi acrescentada uma testemunha que não recebeu nenhum dos tratamentos. Foram avaliados comprimento e diâmetro do primeiro e segundo fluxo de brotação após a poda,índice SPAD e os teores foliares de amido e açúcares solúveis totais, cujas amostras foram colhidas no período de intumescimento das gemas (época 1) e aos 60 dias após o florescimento pleno (época 2). O PBZ não influenciou no crescimento dos ramos e na intensidade da cor verde em mangueira 'Ubá', porém alterou os teores dos carboidratos em mangueira 'Ubá'.

Palavras-chave: Mangifera indica L, Regulador de crescimento, Amido e Açúcares solúveis.

\begin{abstract}
A B S T R A C T
The use of paclobutrazol in mango tree is very widespread in the tropical regions, since they play an important role in promoting flowering, allowing production to be staggered. In addition to flowering, paclobutrazol may influence other characteristics, such as size, carbohydrate concentration and change in the green color on the leaves. The work aimed to study the possible relationship between vegetative characteristics and carbohydrate concentrations in mango plants 'Uba' submitted to different doses of paclobutrazol (PBZ). In April 2014 the PBZ was applied in mango trees 'Uba', conducted in factorial arrangement $(5 \times 2)+1$, being 5 paclobutrazol doses $(0,0.50,1.00,1.50$ and $2.0 \mathrm{~g}$ (ai) per linear meter of tree top) with and without tip pruning branches. The design was randomized blocks with four repetitions and to each block was added a control treatment that has not received any of the treatments described above. It were evaluated length and diameter of the first and second budding flow, SPAD and leaf contents of starch and total soluble sugars, which samples were taken from the swelling period of gems (time 1) and 60 days after full bloom (time 2). Pruning increased growth of the first budding flow. There was no difference in the diameter of the branches in the growth of the second budding flow and SPAD. The PBZ did not affect the growth of the branches and the intensity of the green color, but changed the proportion of carbohydrates in mango trees 'Uba'.
\end{abstract}

Keywords: Mangifera indica L, Growth regulator, Starch and Soluble sugars. 


\section{INTRODUÇÃO}

O paclobutrazol (PBZ) é um regulador vegetal do grupo dos triazóis, que atua inibindo a síntese de giberelinas. O bloqueio da síntese de giberelinas resulta na redução do crescimento vegetativo e promove a floração da mangueira (Mouco et al., 2011). O uso do paclobutrazol em mangueiras é bastante difundido nas regiões tropicais, sendo aplicado via solo, geralmente após uma poda (Upreti et al., 2013), uma vez que desempenham importante função na indução floral, permitindo o escalonamento da produção durante o ano e atendendo aos diversos mercados disponíveis.

Além da floração, o paclobutrazol pode influenciar outras características das mangueiras, como porte, concentração de carboidratos (Cruz et al., 2007) e alterar a cor verde nas folhas (Siqueira et al., 2008).

A intensidade da cor verde nas folhas das mangueiras é avaliada com o clorofilómetro e os resuldados expressos em índice SPAD. Na maioria dos casos, esse índice apresenta correlação positiva com os teores de clorofila nas folhas (Klooster et al., 2012). Os efeitos do paclobutrazol sobre o crescimento vegetativo, teores de carboidratos e índice SPAD parecem variar não só em função da concentração aplicada, mas também em função da cultivar de mangueira e da resposta ao florescimento.
Segundo Santos-Villalobos et al. (2013), o florescimento em mangueiras pode ser regulado por fatores hormonais e por carboidratos. Hormonas como as auxinas, citocininas e giberelinas parecem regular a sincronização do desenvolvimento de gemas, bem como a diferenciação no seu desenvolvimento como gema floral ou vegetativa. Além disso, a indução do florescimento pode ser resultante da acumulação de níveis ótimos de carboidratos nas gemas, os quais, associados a supostos estímulos florais, desencadeariam a indução floral (Davenport, 2007).

Nesse contexto, esse trabalho teve o objetivo de avaliar as mudanças fenotípicas da planta (crescimento vegetativo, intensidade da cor verde nas folhas e florescimento) e estudar as possíveis alterações nos teores de carboidratos nas folhas de mangueira 'Ubá' em função da aplicação de diferentes doses de paclobutrazol.

\section{MATERIAL E MÉTODOS}

O experimento foi conduzido com a mangueira 'Ubá' em Pomar experimental localizado em Viçosa, MG, pertencente ao Departamento de Fitotecnia da Universidade Federal de Viçosa, situada na longitude $42^{\circ} 52^{\prime} 40^{\prime \prime}$ Oeste e latitude $20^{\circ} 45^{\prime} 20^{\prime \prime}$ Sul e altitude de 651 metros. O clima da

Quadro 1 - Resultados analíticos do solo coletado na área experimental, em duas profundidades

\begin{tabular}{|c|c|c|c|c|c|c|c|c|c|c|c|c|c|}
\hline \multicolumn{14}{|c|}{ Composição química } \\
\hline \multirow[t]{2}{*}{$\mathrm{cm}$} & $\mathrm{pH}$ & $\mathbf{P}$ & $\mathbf{K}$ & \multirow[t]{2}{*}{$\mathrm{Ca}$} & $\mathrm{Mg}$ & Al & $\mathrm{H}+\mathrm{Al}$ & SB & $t$ & $\mathrm{~T}$ & \multirow{2}{*}{\multicolumn{2}{|c|}{$\begin{array}{l}\mathrm{V} \\
\end{array}$}} & \multirow{2}{*}{$\begin{array}{l}\text { Prem } \\
\mathrm{mg} / \mathrm{L}\end{array}$} \\
\hline & $\mathrm{H}_{2} \mathrm{O}$ & \multicolumn{2}{|c|}{$\ldots \ldots \mathrm{mg} / \mathrm{dm}^{3} \ldots .}$. & & $\ldots$ & ............ & \multicolumn{4}{|c|}{ 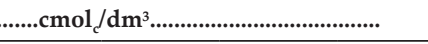 } & & & \\
\hline $0-20$ & 5,0 & 6,6 & 24 & 0,7 & 0,3 & 0,5 & 4,29 & 1,06 & 1,56 & 5,35 & 20 & 32 & 28,6 \\
\hline $20-40$ & 4,8 & 5,1 & 13 & 0,4 & 0,2 & 0,9 & 4,13 & 0,63 & 1,53 & 4,76 & 13 & 59 & 26,0 \\
\hline
\end{tabular}

Quadro 2 - Resultados analíticos das folhas das mangueiras 'Ubá’ usadas no experimento

\begin{tabular}{|c|c|c|c|c|c|c|c|c|c|c|}
\hline \multicolumn{11}{|c|}{ Composição Química } \\
\hline $\mathbf{N}$ & $\mathbf{P}$ & K & $\mathrm{Ca}$ & $\mathrm{Mg}$ & $\mathrm{s}$ & $\mathrm{Zn}$ & $\mathrm{Fe}$ & Mn & $\mathrm{Cu}$ & B \\
\hline$\ldots$ & $\ldots . . \mathrm{g} / \mathrm{kg}$ & $\ldots \ldots \ldots . . . .$. & & & & $\ldots$ & $\mathrm{mg} / \mathrm{kg}$ & $\ldots \ldots \ldots \ldots . . .$. & & \\
\hline 16,0 & 0,95 & 5,6 & 12,0 & 1,6 & 1,2 & 14,5 & 122 & 364,5 & 6,5 & 18,7 \\
\hline
\end{tabular}


região, segundo a classificação de Kopen, é do tipo Cwa, mesotérmico, com verões quentes e chuvosos e com período de inverno frio e seco. A pluviosidade média anual é de $1360 \mathrm{~mm}$ e a temperatura média anual é de $22,8^{\circ} \mathrm{C}$ (INMET, 2015). As análises de solo da área experimental e foliares das mangueiras estão apresentadas nos quadros 1 e 2 respectivamente.

O pomar de mangueiras 'Ubá' foi implantado em março de 2010, em espaçamento de 7 x 6 m. Em 13 de dezembro de 2013, foi realizada a poda de ponteiros dos ramos, cujo objetivo foi uniformizar a brotação quanto ao vigor e idade dos ramos, eliminar os ramos doentes, pouco vigorosos e mal localizados. Também foi realizado a abertura central e o levantamento da copa das árvores.

O pomar não recebeu irrigação durante todo o período experimental porque o objetivo foi conduzir o trabalho usando as mesmas condições de cultivo da mangueira 'Ubá' na Zona da Mata Mineira.

O experimento foi em esquema fatorial $5 \times 2+1$, sendo o primeiro fator cinco doses de paclobutrazol $(0 ; 0,50 ; 1,00 ; 1,50$ e 2,0 g por metro linear de copa), e o segundo fator o desponte dos ramos (com e sem desponte). Foi adicionado um tratamento testemunha que não recebeu poda e nenhum dos tratamentos. O delineamento experimental usado foi o de blocos casualizados com quatro repetições e uma planta por parcela.

Em 11 de abril de 2014, após dois fluxos de brotação, foi aplicado o paclobutrazol via solo para reduzir o crescimento vegetativo, evitar emissão do terceiro fluxo de crescimento e promover a floração. A fonte de paclobutrazol (PBZ) foi o Cultar 250 SC (Syngenta), com 25\% de ingrediente ativo. O produto comercial contendo PBZ foi diluído em dois litros de água, de acordo com as doses calculadas, e aplicado, em rega, na projeção da copa.

Para auxiliar a maturação dos ramos foram realizadas três aplicações de sulfato de potássio $\left(\mathrm{K}_{2} \mathrm{SO}_{4}\right)$ na concentração de 3\%, em 4 litros de calda por planta. As primeiras aplicações foram realizadas aos 50 e 57 dias após a aplicação do paclobutrazol. A última aplicação foi realizada passados 12 dias, acrescida de ethephon (Ethrel 720) na dosagem de
$50 \mathrm{ml}$ para cada 100 litros de água. Após 75 dias da aplicação do PBZ fez-se o desponte dos ramos, de acordo com os tratamentos, a aproximadamente $5 \mathrm{~cm}$ abaixo do seu ápice.

A partir do desponte das plantas, iniciou-se a aplicação do nitrato de cálcio, aos 90 dias após a aplicação de PBZ, com intuito de induzir a brotação, na concentração de $2 \%$ no volume de 4 litros de calda por planta. Foram feitas quatro aplicações que ocorreram nos dias 03, 10, 17 e 24 de julho de 2014.

Foram feitas avaliações de comprimento e diâmetro dos ramos brotados após a poda em cada fluxo, índice SPAD, teores de carboidratos nas folhas e percentagem de florescimento.

Para o comprimento e diâmetros dos ramos, índice SPAD as plantas foram divididas em quatro quadrantes e foram marcados doze ramos por planta (três ramos por quadrante). Foram avaliados comprimento e diâmetro do primeiro fluxo vegetativo 60 dias após a poda, antes da aplicação do paclobutrazol, quando os ramos estavam maduros e antes de ocorrer o inicio da brotação do segundo fluxo. O crescimento e o diâmetro dos ramos do segundo fluxo vegetativo foram avaliados quando os ramos estavam maduros, o que ocorreu aos 60 dias após a aplicação do paclobutrazol.

Aos 50 após a aplicação do paclobutrazol foi realizada a primeira leitura do índice SPAD com o medidor portátil SPAD-502 [Soil-Plant Analysis Development (SPAD) Section, Minolta Camera Co., Ltd., Japão]. Foram utilizadas duas folhas maduras,completamente expandidas,do segundo fluxo de brotação ( $4^{\mathrm{a}}$ folha a partir do ápice para base do ramo), de cada quadrante, totalizando oito leituras por planta. Outra avaliação do índice SPAD foi realizada no pleno florescimento das plantas, 140 dias após a aplicação do paclobutrazol.

Foram avaliados os teores foliares de amido (a) e açúcares solúveis totais (as), cujas amostras foram colhidas em dois períodos: 10/07/2014 durante o período de intumescimento das gemas de floração e 15/11/2014, durante o período de desenvolvimento dos frutos. Foram coletadas duas folhas maduras do segundo fluxo de brotação ( $4^{\mathrm{a}}$ folha contada a partir do ápice do ramo), completamente expandidas, de cada quadrante, totalizando oito folhas 
por planta. Depois de coletadas, foram levadas ao laboratório, onde foram lavadas, enxaguadas e secas em papel toalha. Em seguida as folhas foram desidratadas em estufa de circulação forçada, a $60^{\circ} \mathrm{C}$, até atingirem peso constante.

Posteriormente, as amostras de cada tratamento foram moídas em moinho tipo Willey, de aço inoxidável, passadas em peneira de 0,84 milímetros, e acondicionadas em frascos para posterior análise química.

A obtenção do extrato e a determinação das concentrações de açúcares solúveis totais e amido foram realizadas pelo método antrona sulfúrico, descrito por McCready et al. (1950).

Os dados obtidos foram submetidos à análise de variância. Para as características com diferenças significativas foi realizado o teste Dunnett para comparar com a testemunha. Os efeitos das doses de reguladores de crescimento foram testados e ajustados em equação de regressão. O programa estatístico utilizado foi o Sistema de Análises Estatísticas e Genéticas da Universidade Federal de Viçosa (SAEG, 2007).

\section{RESULTADOS E DISCUSSÃO}

Todas as plantas emitiram dois fluxos de brotação vegetativa após a poda realizada depois da colheita dos frutos, em dezembroe apenas $10 \%$ das plantas chegaram a emitir o terceiro fluxo vegetativo. O comprimento dos ramos do primeiro fluxo, 60 dias após a poda, foi menor nas plantas testemunha, apresentando $16,3 \mathrm{~cm}$ em média, sem poda, em comparação aos demais tratamentos com poda que apresentou $30 \mathrm{~cm}$ em média.

A poda foi realizada em dezembro de 2013 , justamente no período de maior pluviosidade e altas temperaturas médias que favoreceram o crescimento vegetativo da planta. $\mathrm{O}$ teor de $\mathrm{N}$ foliar (Quadro 2) que foi de $16 \mathrm{~g} / \mathrm{kg}$, associados à adubação de solo e às condições climáticas favoráveis ao desenvolvimento vegetativo foi determinante para o maior crescimento dos ramos e emissão de três fluxos, em algumas plantas, conforme mencionado anteriormente.
A poda aumenta significativamente o número de novas brotações; entretanto um ou mais fluxos vegetativos podem ocorrer naturalmente, dependendo da cultivar, idade da árvore, altos teores de azoto foliar e condições climáticas favoráveis (Davenport, 2007; Shaban, 2009; Garcia de Niz et al., 2014). De salientar que o crescimento vegetativo é determinante para a produção, pois quanto mais abundantes forem as brotações vegetativas, maior será a probabilidade de emissão de panículas e maior a frutificação. Na prática, isso significa que é interessante estimular o mais cedo possível, após a colheita, a emissão de novos fluxos vegetativos através da poda de ponteiros, manejo nutricional e irrigação (Davenport, 2006).

Não houve diferença significativa nas médias do comprimento do segundo fluxo de brotação vegetativa e no diâmetro dos ramos do primeiro e segundo fluxo de brotação vegetativa (Quadro 3).

Mouco et al. (2011) e Oliveira et al. (2015) relatam que o primeiro efeito da aplicação do paclobutrazol é a paralisação do crescimento vegetativo das mangueiras, afetando os fluxos novos e reduzindo o crescimento dos ramos; no entanto, para a mangueira 'Ubá' e para as doses do paclobutrazol aplicadas não foi possível conter o crescimento vegetativo do segundo fluxo de brotação dos ramos. A cultivar Ubá é muito vigorosa e tem a capacidade de vegetar intensamente, o que dificulta conter o crescimento vegetativo. No entanto para produção é importante o manejo do crescimento vegetativo, já que, evitando-se a brotação excessiva, pode-se promover a floração e a frutificação precoce em plantas jovens (Davenport, 2007).

A aplicação de diferentes doses do paclobutrazol não alterou a intensidade da cor verde em plantas de mangueira 'Ubá' medidas através do índice SPAD (Quadro 4).

Esses resultados diferem dosencontradosem alguns trabalhos que observaram a maior intensidade da cor verde em folhas de plantas de limoeiro'Volkameriano' e de algodão tratadas com paclobutrazol (Siqueira et al., 2008; Silva et al., 2014). Segundo Davies e Sankhla (1987) o aumento nos teores de clorofila pode ser ocasionado pelo efeito "concentrador" de clorofila devido à redução da expansão foliar. A falta de resposta quanto à cor verde pode 
Quadro 3 - Valores médios do comprimento de ramos do primeiro (COMP1) e segundo (COMP2) fluxo de brotação, diâmetro de ramos do primeiro (DIAM1) e segundo (DIAM2) fluxo de brotação de mangueiras 'Ubá' submetidas a diferentes doses de paclobutrazol, com e sem desponte dos ramos

\begin{tabular}{|c|c|c|c|c|c|c|}
\hline & \multicolumn{2}{|c|}{ Tratamento } & \multirow{2}{*}{$\begin{array}{l}\text { COMP1 } \\
(\mathrm{cm})\end{array}$} & \multirow{2}{*}{$\begin{array}{c}\text { COMP2 } \\
(\mathrm{cm})\end{array}$} & \multirow{2}{*}{$\begin{array}{c}\text { DIAM1 } \\
(\mathrm{mm}) \\
\end{array}$} & \multirow{2}{*}{$\begin{array}{c}\text { DIAM2 } \\
\text { (mm) }\end{array}$} \\
\hline & $\begin{array}{l}\text { Dose } \\
\left(\mathrm{g} \mathrm{m}^{-1}\right)\end{array}$ & Desponte & & & & \\
\hline T1 & 0,0 & com & $27,68^{*}$ & 24,50 & 5,33 & 6,70 \\
\hline $\mathrm{T} 2$ & 0,0 & sem & $30,00^{*}$ & 25,20 & 5,44 & 6,53 \\
\hline T3 & 0,5 & com & $30,90^{*}$ & 25,79 & 5,80 & 6,68 \\
\hline $\mathrm{T} 4$ & 0,5 & sem & $25,71^{*}$ & 20,16 & 5,56 & 6,01 \\
\hline T5 & 1,0 & com & $29,26^{*}$ & 29,25 & 5,76 & 6,81 \\
\hline $\mathrm{T} 6$ & 1,0 & sem & $29,28^{*}$ & 26,14 & 5,13 & 6,33 \\
\hline $\mathrm{T} 7$ & 1,5 & com & $28,68^{*}$ & 25,06 & 5,59 & 6,34 \\
\hline $\mathrm{T} 8$ & 1,5 & sem & $31,32^{*}$ & 26,22 & 5,68 & 6,50 \\
\hline T9 & 2,0 & com & $30,06^{*}$ & 25,75 & 5,70 & 6,46 \\
\hline $\mathrm{T} 10$ & 2,0 & sem & $30,92^{*}$ & 26,58 & 5,82 & 6,75 \\
\hline \multirow[t]{2}{*}{ T11 } & Controle & - & 16,43 & 22,45 & 5,16 & 6,28 \\
\hline & Média geral & & 27,93 & 25,19 & 5,54 & 6,49 \\
\hline
\end{tabular}

* As médias na coluna diferem da testemunha ao nível de $5 \%$ de probabilidade pelo teste Dunnett.

estar relacionada com a falta de resposta à redução no crescimento do segundo fluxo de brotação das mangueiras 'Ubá' (Quadro 3) não ocorrendo assim o "efeito concentrador" dos teores de clorofila nas folhas. Embora a área foliar não tenha sido medida, visualmente não foi observada redução na área foliar devido à aplicação do paclobutrazol.

Quadro 4 - Valores médios dos índices SPAD após 60 dias de aplicação do paclobutrazol (SPAD 1) e no período do florescimento (SPAD 2) aos 142 dias após aplicação de PBZ, em mangueira 'Ubá' submetidas a diferentes doses de paclobutrazol e desponte dos ramos

\begin{tabular}{|c|c|c|c|c|}
\hline \multicolumn{3}{|c|}{ Tratamento } & \multirow[t]{3}{*}{ SPAD1 } & \multirow[t]{3}{*}{ SPAD2 } \\
\hline & Dose & \multirow[b]{2}{*}{ Desponte } & & \\
\hline & $\left(\mathrm{g} \mathrm{m}^{-1}\right)$ & & & \\
\hline $\mathrm{T} 1$ & 0,0 & com & 57,97 & 54,52 \\
\hline $\mathrm{T} 2$ & 0,0 & sem & 58,10 & 54,67 \\
\hline $\mathrm{T} 3$ & 0,5 & com & 57,33 & 55,31 \\
\hline $\mathrm{T} 4$ & 0,5 & sem & 56,25 & 52,54 \\
\hline $\mathrm{T} 5$ & 1,0 & com & 60,02 & 53,71 \\
\hline T6 & 1,0 & sem & 58,53 & 54,25 \\
\hline $\mathrm{T} 7$ & 1,5 & com & 55,33 & 55,78 \\
\hline $\mathrm{T} 8$ & 1,5 & sem & 60,19 & 56,37 \\
\hline T9 & 2,0 & com & 57,78 & 52,80 \\
\hline $\mathrm{T} 10$ & 2,0 & sem & 60,30 & 55,96 \\
\hline $\mathrm{T} 11$ & Controle & & 57,71 & 57,60 \\
\hline \multicolumn{2}{|c|}{ Média geral } & & 58,13 & 54,86 \\
\hline
\end{tabular}

No período de intumescimento das gemas florais os teores foliares de açúcares solúveis totais reduziram e foram ajustados por uma equação quadrática em função de diferentes doses de paclobutrazol. O menor teor de açúcares solúveis encontrado nas folhas de mangueira 'Ubá' foi de $33 \mathrm{mg} \mathrm{g}^{-1}$ de matéria seca, que correspondeu à dose de 1,76 g de paclobutrazol por metro linear da copa das plantas (Figura 1A). Os teores de amido na época de intumescimento das gemas florais permaneceram constantes e a média geral foi de $45 \mathrm{mg} \mathrm{g}^{-1}$ de matéria seca nas folhas (Figura 1B).

Os teores de carboidratos nas folhas estão envolvidos no desenvolvimento da panícula e na intensidade da indução do florescimento (Davenport, 2007), portanto, a redução nos teores de açúcares solúveis totais pode ter ocorrido em função da demanda energética para formação das inflorescências.

Nessa época, provavelmente foi iniciada a translocação dos carboidratos necessários para a formação das panículas, utilizando os açúcares solúveis para respiração e síntese de moléculas necessárias para o florescimento. Como as plantas ainda não estavam em pleno florescimento, provavelmente ainda não havia necessidade de utilização das reservas de amido nas plantas (Cruz et al., 2007). 

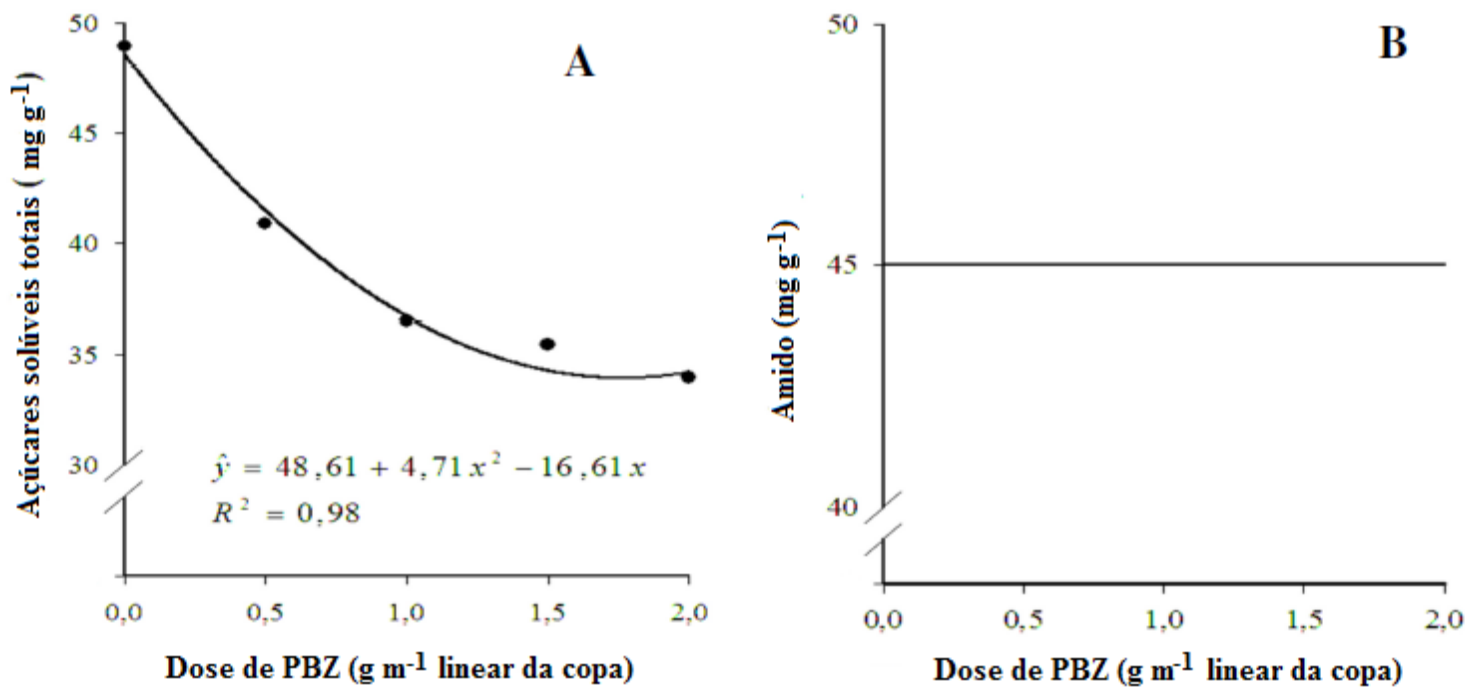

Figura 1 - Teores de açúcares solúveis totais (A) e teores de amido (B) nas folhas nas mangueiras 'Ubá' submetidas a diferentes doses de paclobutrazol e desponte dos ramos na época de intumescimento das gemas de florescimento.

No período de desenvolvimento dos frutos, não houve alteração nos teores de açúcares solúveis totais, cuja média geral foi de $37 \mathrm{mg} \mathrm{g}^{-1}$ de matéria seca nas folhas (Figura 2A), porém houve redução significativa nos teores de amido em resposta ao incremento das doses de PBZ (Figura 2B). Para a dose de $2 \mathrm{~g}$ por metro linear de copa a redução dos teores de amido foi cerca de $45 \%$ em relação à dose zero.
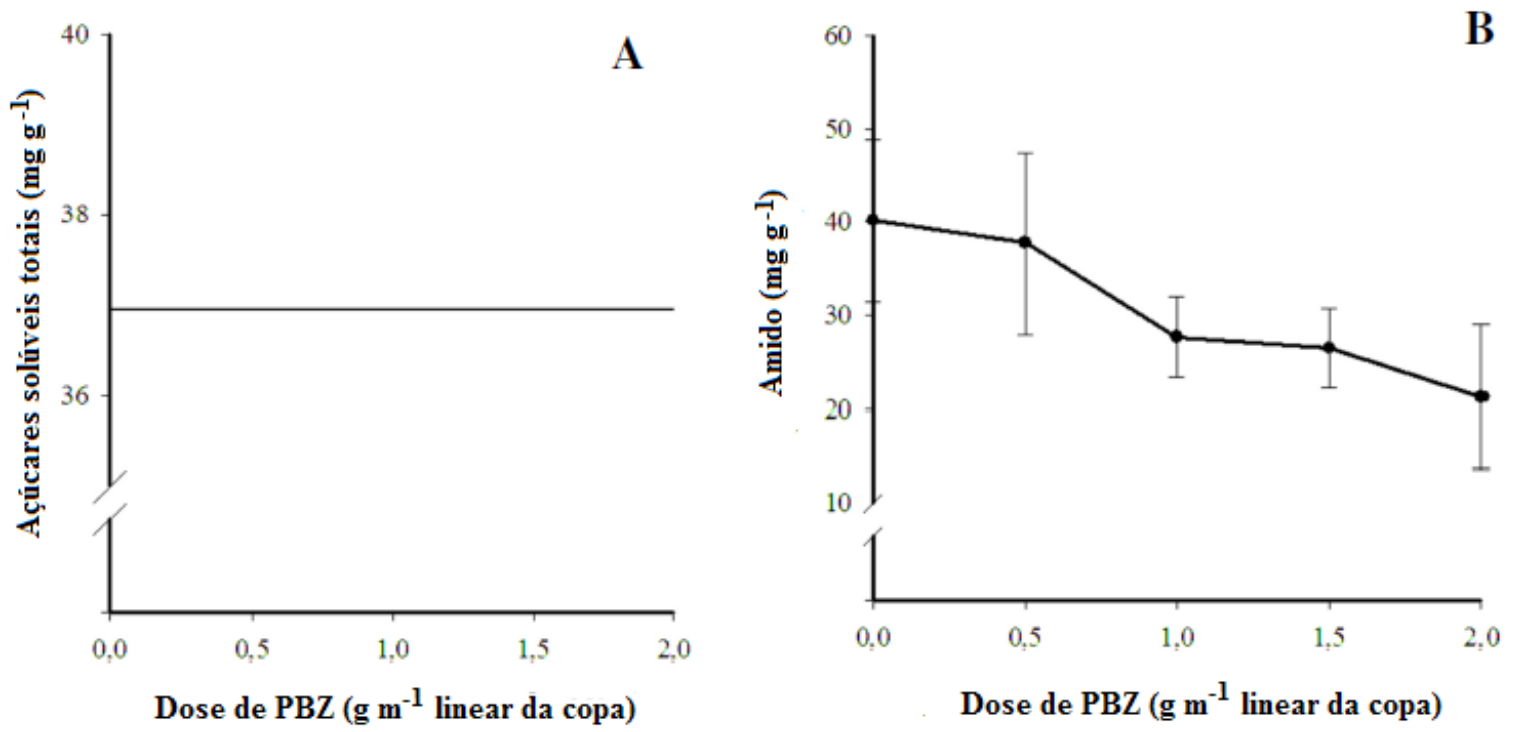

Figura 2 - Teores de açúcares solúveis totais (A) e teores de amido (B) nas folhas de mangueira 'Ubá’ submetidas a diferentes doses de paclobutrazol e desponte dos ramos na época de desenvolvimento dos frutos. 
Nessa fase, as plantas já estavam com frutos, que são drenos que possuem intensa capacidade de mobilizar fotoassimilados em sua direção, aumentando a demanda para utilização das reservas de amido. $\mathrm{O}$ amido necessita ser convertido em açúcares para ser translocado pelo floema (Taiz e Zeiger, 2012), portanto, os teores de amido reduziram porque foram convertidos em açúcares solúveis, não alterando assim os teores de açúcares solúveis. Cruz et al. (2007), ao avaliarem os teores de carboidratos em folhas de limeira 'Tahiti' tratadas com PBZ, também constataram decréscimo nos teores de amido e açúcares solúveis.

Segundo Oliveira et al. (2013), ocorre consumo de carboidratos por ocasião das brotações e emissão de flores. O paclobutrazol induz o florescimento nas plantasde mangueira 'Ubá' e aumenta a produção de flores (Oliveira et al., 2015, 2017) e consequentemente provoca o aumento do consumo de carboidratos para formação e desenvolvimento das panículas, resultando em menores teores de carboidratos nas folhas. Santos-Villalobos et al. (2013), trabalhando com mangueiras 'Ataulfo', observaram que os teores de carboidratos decresceram com o tempo, sugerindo que esses foram consumidos para o desenvolvimento da panícula e dos frutos.

A intensidade das brotações em plantas com manejo de poda (Figura 1) após a colheita interfere nas reservas das plantas. Nas plantas podadas pode haver maior mobilização de reservas de carboidratos para sustentar o crescimento das novas brotações reduzindo o acúmulo de carboidratos (Kalil et al., 1999). As plantas testemunha (sem poda) não brotaram intensamente, então provavelmente tiveram menor gasto de reservas para suprir as novas brotações, necessitando de um menor intervalo de tempo para acumular os carboidratos e florescer.

\section{CONCLUSÕES}

A poda após a colheita aumentou a intensidade de brotação vegetativa na mangueira 'Ubá'.

As doses testadas de paclobutrazol não alteraram as características de crescimento dos ramos e intensidade da cor verde nas folhas.

O decréscimo de carboidratos foi observado nas plantas tratadas com paclobutrazol.

O incremento na dose de paclobutrazol reduziu os teores de açúcares solúveis totais nas folhas de mangueira na época de intumescimento das gemas florais e reduziu os teores de amido nas folhas na época de frutificação.

\section{REFERÊNCIAS BIBLIOGRÁFICAS}

Cruz, M.C.M.; Siqueira, D.L.; Salomão, L.C.C.; Cecon, P.R. \& Santos, D. (2007) - Teores de carboidratos em limeiras ácidas 'Tahiti' tratadas com paclobutrazol. Revista Brasileira de Fruticultura, vol. 29, p. 222-227. http://dx.doi.org/10.1590/S0100-29452007000200007

Davenport, T.L. (2006) - Pruning Strategies to Maximize Tropical Mango Production from the Time of Planting to Restoration of Old Orchards. Hortscience, vol. 41, n. 3, p. 544-548.

Davenport, T.L. (2007) - Reproductive physiology of mango. Brazilian Journal of Plant Physiology, vol. 19, n. 4, p. 363-376. http://dx.doi.org/10.1590/S1677-04202007000400007

Davies, T.D. \& Sankhla, N. (1987) - Altered diurnal leaf movements in soybean seedlings treated with triazole growth regulators. Plant Cell Physiology, vol. 28, n. 7, p. 1345-1349. https://doi.org/10.1093/oxfordjournals. pcp.a077425

Garcia De Niz, D.A.; Esquivel, G.L.; Montoya, R.B.; Arrieta Ramos, B.G.; Santiago, G.A.; Gómez Aguilar, J.R. \& Sao José, A.R. (2014) - Vegetative and reproductive development of 'Ataulfo' Mango under pruning and Paclobutrazol Management. Journal of Agricultural Science and Technology, vol. 16, n. 2, p. 385-393.

Kalil, G.P.C.; Terra, M.M.; Filho, A.N.K.; Macedo, J.L.V. \& Pires, E.J.P. (1999) - Anelamento e ácido giberélico na frutificação da uva 'Maria' sem sementes. Scientia Agricola, vol. 56, n. 2, p. 317-328. http://dx.doi.org/10.1590/ S0103-90161999000200010 
Klooster, W.S.; Cregg, B.M.; Fernandez, R.T. \& Nzokou, P. (2012) - Growth and physiology of deciduous shade trees in response to controlled release fertilizer. Scientia Horticulturae, vol. 35, p. 71-79. https://doi. org/10.1016/j.scienta.2011.12.009

McCready, R.M.; Guggolz, J.; Silveira, V. \& Owens, H.S. (1950) - Determination of starch and amylase in vegetables. Application to peas. Analytical Chemistry, vol.22, n. 9, p. 1156-1158. https://doi.org/10.1021/ ac60045a016

Mouco, M.A.C.; Ono, E.O.O. \& Rodrigues, J.D.(2011) - Controle do crescimento vegetativo e floração de mangueira cv. Kent com reguladores de crescimento vegetal. Revista Brasileira de Fruticultura, vol. 33, n. 4, p. 1043-1047. http://dx.doi.org/10.1590/S0100-29452011000400001

Oliveira, D.L.; Cruz, M.C.M.; Oliveira, A.F.; Chalfun, N.N.J. \& Alvarenga, A.A. (2013) - Teores de carboidratos e indução do florescimento em mudas de oliveira submetidas a aplicação de paclobutrazol. Scientia Agraria Paranaensis, vol. 12, n. 3, p. 221-226.

Oliveira, G.P.; Siqueira, D.L.; Salomão, L.C.C.; Cecon, C.R. \& Magalhães, D.L.M. (2017) - Paclobutrazol e desponte dos ramos no florescimento e qualidade de frutos de mangueira. Pesquisa Agropecuária Tropical, vol. 47, n. 1, p. 7-14.

Oliveira, M.B.; Pereira, M.C.T.; Mizobutsi, G.P.; Maia, V.M.; Silva, J.F.; Oliveira, J.A.A.; Costa, I.J.S.; Nietsche, S.; Santos, E.F. \& Mouco, M.A.C. (2015) - Paclobutrazol and tip pruning in the management of 'palmer' mango trees in the semi-arid region of Brazil. Acta Horticulturae, vol. 1075, p. 149-156.

SAEG (2007) - Sistema para análise estatística. Versão 9.1. Viçosa, MG: Fundação Arthur Bernardes, UFV.

Santos-Villalobos, S.; Folter, S.; Delano-Frier, J.; Gómez-Lim, M. \& Guzmán-Ortiz, D. (2013) - Growth Promotion and Flowering Induction in Mango (Mangifera indica L. cv. "Ataulfo") Trees by Burkholderia and Rhizobium Inoculation: Morphometric, Biochemical, and Molecular Events. Journal of Plant Growth Regulation, vol. 32, n. 3, p. 615-627. https://doi.org/10.1007/s00344-013-9329-5

Shaban, A.E.A. \& Haseeb, G.M.M. (2009) - Effect of Pruning Severity and Spraying Some Chemical Substances on Growth and Fruiting of Guava Trees. Journal of Agricultural \& Environmental Sciences, vol. 5, p. 825-831.

Silva, K.K.A.; Ono, E.O.; Mouco, M.A.C.; Silva, G.J.N.; Souza, R.J.M.; Silva, N.C. \& Silva, R.C.B. (2014) Uniconazole no florescimento e produção da mangueira (Mangifera indica L.) cv. Palmer. Revista Megistra, vol. 26, p. 507-517.

Siqueira, D. L. de; Cecon, p. R. \& Salomão, L.C.C. (2008) - Desenvolvimento do limoeiro 'Volkameriano' (Citrus volkameriana Pasq.) submetido a doses de paclobutrazol e ácido giberélico. Revista Brasileira de Fruticultura, vol. 30, n. 3, p.764-768. http://dx.doi.org/10.1590/S0100-29452008000300034

Taiz, L \& Zeiger, E. (2012) - Fisiologia vegetal. 5. ed. Porto Alegre: Artmed, 954 p.

Upreti, K.K.; Reddy, Y.T.N.; Prasad, S.R.S.; Bindu, G.V.; Jayaram, H.L. \& Rajan, S.(2013) - Hormonal changes in response to paclobutrazol induced early flowering in mango cv. Totapuri. Scientia Horticulturae, vol. 150, p. 414-418. https://doi.org/10.1016/j.scienta.2012.11.030 